\title{
Synthesis and Characterization of Novel Brønsted-Lewis Acidic Ionic Liquids
}

\author{
Hualiang An, Lijuan Kang, Wei Gao, Xinqiang Zhao", Yanji Wang \\ Hebei Provincial Key Lab of Green Chemical Technology and High Efficient Energy Saving, \\ Hebei University of Technology, Tianjin, China \\ Email: ${ }^{*}$ zhaoxq@hebut.edu.cn
}

Received March 18, 2013; revised April 20, 2013; accepted April 27, 2013

Copyright (C) 2013 Hualiang An et al. This is an open access article distributed under the Creative Commons Attribution License, which permits unrestricted use, distribution, and reproduction in any medium, provided the original work is properly cited.

\begin{abstract}
To meet the demands of some kinds of reactions catalyzed simultaneously by Brønsted acid and Lewis acid catalyst, two novel Brønsted-Lewis acidic ionic liquids, 1-carboxyethylene-3-(4-zinc acetate sulfobutyl) imidazolium chloride $\left(\left[\mathrm{CH}_{3} \mathrm{COO}-\mathrm{Zn}-\mathrm{O}_{3} \mathrm{~S}-\right.\right.$ bim- $\left.\left.\mathrm{CH}_{2} \mathrm{CH}_{2} \mathrm{COOH}\right] \mathrm{Cl}\right)$ and 1-(1,2-dicarboxy) ethylene-3-(4-zinc acetate sulfobutyl) imidazolium chloride $\left(\left[\mathrm{CH}_{3} \mathrm{COO}-\mathrm{Zn}-\mathrm{O}_{3} \mathrm{~S}\right.\right.$-bim- $\left.\left.\mathrm{C}_{4} \mathrm{H}_{5} \mathrm{O}_{4}\right] \mathrm{Cl}\right)$ were synthesized, in which both Brønsted and Lewis acidic sites existed in the cation. The structures of the ionic liquids were determined by means of FT-IR, ${ }^{1} \mathrm{H}$ NMR and elemental analysis. The results of Py-IR analysis indicated that the two novel ionic liquids have both Brønsted and Lewis acid properties. The acid strength values $\left(H_{0}\right)$ of the ionic liquids were measured utilizing the UV-visible spectroscopy combined with Hammett indicator method, and the acid amount of them was determined by acid-base titration.
\end{abstract}

Keywords: Brønsted-Lewis Acidic Ionic Liquids; Synthesis; Characterization

\section{Introduction}

Ionic liquids, due to their strong dissolving capacity, negligible vapor pressure, high thermal and chemical stability, have attracted much attention. The emergence of functionalized ionic liquids extends the application fields of ionic liquids. Acidic ionic liquids are a kind of functionalized ionic liquids, and recently have attracted more interests due to their advantages of both solid acid and liquid acid.

The traditional acidic ionic liquids include Brønsted acidic ionic liquids and Lewis acidic ionic liquids. Lewis acidic ionic liquids are usually prepared from metal halides and organic halides, and the most representative one of them is chloroaluminate ionic liquid. However, chloroaluminate ionic liquid is sensitive to moisture and unstable, so $\mathrm{FeCl}_{3}$ or other metal halide gradually takes the place of $\mathrm{AlCl}_{3}$ to prepare Lewis acidic ionic liquids which are not sensitive to water [1]. As compared with Lewis acidic ionic liquids, Brønsted acidic ionic liquids are synthesized later. Cole et al. [2] reported the synthesis of Brønsted acidic ionic liquids for the first time in 2002, and then the studies on Brønsted acidic ionic liquids developed rapidly. The traditional acidic ionic liquids men-

\footnotetext{
"Corresponding author.
}

tioned above possess just single Lewis or Brønsted acid sites, which can not meet the demands of some reactions catalyzed simultaneously by Brønsted acid and Lewis acid catalyst, e.g. one-pot synthesis of methylene diphenyl dimethylcarbamate from aniline, dimethyl carbonate and formaldehyde [3]. Wang et al. [4] reported a dual acidic ionic liquid $\left[\mathrm{C}_{4} \mathrm{SC}_{\mathrm{n}} \mathrm{im}\right] \mathrm{Cl}-\mathrm{AlCl}_{3}$ first in 2005. The acidity of the dual acidic ionic liquid was determined by IR spectrography using pyridine as a probe, and the result showed that $\left[\mathrm{C}_{4} \mathrm{SC}_{\mathrm{n}} \mathrm{im}\right] \mathrm{Cl}-\mathrm{AlCl}_{3}$ was indeed a dual acidic ionic liquid. Liu et al. [5,6] synthesized a Brønsted-Lewis acidic ionic liquid $\left[\mathrm{HSO}_{3}-\left(\mathrm{CH}_{2}\right)_{3}-\mathrm{NEt}_{3}\right] \mathrm{Cl}-$ $\mathrm{ZnCl}_{2}$ and evaluated its catalytic performance in rosin dimerization and fatty acid methyl ester dimerization, respectively. They [7-9] also prepared another BrønstedLewis acidic ionic liquid $\left[\mathrm{HO}_{3} \mathrm{~S}-\left(\mathrm{CH}_{2}\right)_{3}-\mathrm{mim}\right] \mathrm{Cl}-\mathrm{ZnCl}_{2}$ and used it to catalyze the two reactions mentioned above. Quan et al. [10], Liang et al. [11], and Jiang et al. [12] prepared Brønsted-Lewis acidic ionic liquids $\left[\mathrm{HO}_{3} \mathrm{~S}\right.$ $\left.\left(\mathrm{CH}_{2}\right)_{4}-\mathrm{Py}\right]\left[\mathrm{FeCl}_{4}\right],\left[\mathrm{HO}_{3} \mathrm{~S}-\left(\mathrm{CH}_{2}\right)_{4}-\mathrm{IQ}\right]\left[\mathrm{Cu}_{1 / 2} \mathrm{SO}_{4}\right]$ and $\left[\mathrm{HO}_{3} \mathrm{~S}-\left(\mathrm{CH}_{2}\right)_{4}-\mathrm{Py}\right]\left[\mathrm{Fe}_{1 / 3} \mathrm{SO}_{4}\right]$ respectively, and used them in the reactions of Michael addition. The Brønsted-Lewis acidic ionic liquids reported up till now are those in which the cation contains Brønsted acidity and the anion contains Lewis acidity. To the best of our knowledge, no 
publications about the synthesis of Brønsted-Lewis acidic ionic liquids with both Brønsted and Lewis acidic sites in the cation have been reported.

In this work, two novel Brønsted-Lewis acidic ionic liquids with both Brønsted and Lewis acidic sites in the cation were prepared first, and then their structures and acidity were characterized.

\section{Results and Discussion}

Two novel Brønsted-Lewis acidic ionic liquids, 1-carboxyethylene-3-(4-zinc acetate sulfobutyl) imidazolium chloride $\left(\left[\mathrm{CH}_{3} \mathrm{COO}-\mathrm{Zn}-\mathrm{O}_{3} \mathrm{~S}-\right.\right.$ bim- $\left.-\mathrm{CH}_{2} \mathrm{CH}_{2} \mathrm{COOH}\right] \mathrm{Cl}$, BLILs-1) and 1-(1,2-dicarboxy) ethylene-3-(4-zinc acetate sulfobutyl) imidazolium chloride $\left(\left[\mathrm{CH}_{3} \mathrm{COO}-\mathrm{Zn}-\mathrm{O}_{3} \mathrm{~S}-\right.\right.$ bim- $\left.\mathrm{C}_{4} \mathrm{H}_{5} \mathrm{O}_{4}\right] \mathrm{Cl}$, BLILs-2), were synthesized and characterized in this work.

\subsection{Synthesis Method}

The synthesis approach of BLILs-1 consisted of four-step reactions (Scheme 1). 1-ethoxycarbonylethylene imidazole (Intermediate Product-1, IP-1) was obtained through an addition reaction of imidazole and ethyl acrylate first. Then IP-1 reacted with 1, 4-butane sultone to yield 1ethoxycarbonylethylene-3-(4-sulfobutyl) imidazole (IP-2). The third step was the generation of 1-carboxye-thylene-3-(4-sulfobutyl) imidazolium chloride (IP-3). The Brønsted-Lewis acidic ionic liquid BLILs-1 was synthe sized lastly by the reaction of IP-3 and zinc acetate, and the yield of the target product was $89.6 \%$. In order to improve the acid strength and acid amount, diethyl maleate was used as a substitute for ethyl acrylate to introduce Bronsted acid site in the first step and other steps were similar to that for the synthesis of BLILs-1. Thus another Brønsted-Lewis acidic ionic liquid BLILs-2 was obtained (91.3\% yield). The synthetic route was shown in Scheme 2.

\subsection{Characterization Method}

The structures of the intermediates (IP-2 and IP-3) were determined by means of FT-IR while the structures of intermediates (IP-4, IP-5 and IP-6) were determined by means of ${ }^{1} \mathrm{H}$ NMR analysis. The structures of BLILs-1 and BLILs-2 were characterized by IR, ${ }^{1} \mathrm{H}$ NMR and Elemental analysis, and the results indicated that the structures of the Brønsted-Lewis acidic ionic liquids synthesized in this work were corresponding to those of the target products.

\subsection{Property of Ionic Liquids}

The acidic type of the two ionic liquids was determined by FT-IR using pyridine as a probe (Py-IR). Pyridine can react separately with Brønsted and Lewis acids to produce the cation $[\mathrm{PyH}]^{+}$and the Py-Lewis complex, respectively. $[\mathrm{PyH}]^{+}$has an absorption peak near 1540 $\mathrm{cm}^{-1}$ in the FT-IR spectra, and the absorption peak of Py-<smiles>C=CC(=O)OCC</smiles><smiles>CCOC(=O)CCn1cc[n+](CCCCS(=O)(=O)[O-])c1</smiles>

( IP-2 )<smiles></smiles>

( IP-3 )<smiles></smiles>

(BLILs-1)

Scheme 1. Synthesis route of $\left[\mathrm{CH}_{3} \mathrm{COO}-\mathrm{Zn}-\mathrm{O}_{3} \mathrm{~S}-\mathrm{bim}-\mathrm{CH}_{2} \mathrm{CH}_{2} \mathrm{COOH}\right] \mathrm{Cl}$. 
<smiles>CCOC(=O)C(=O)C(=O)OCC</smiles><smiles>O=S1(=O)CCC[C+]CO1</smiles>

(2)<smiles>CCOC(=O)CC(C(=O)OCC)n1cc[n+](CCCCS(=O)(=O)[O-])c1</smiles>

(IP-5)<smiles></smiles>

(IP-6)

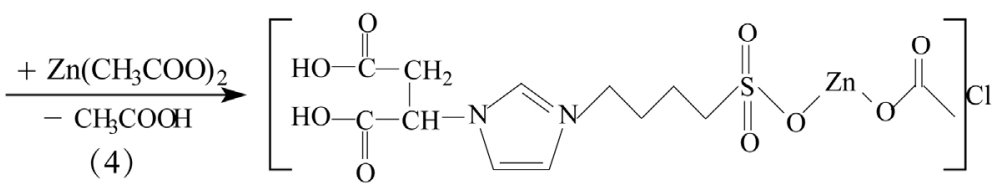

(BLILs-2)

Scheme 2. Synthesis route of $\left[\mathrm{CH}_{3} \mathrm{COO}-\mathrm{Zn}-\mathrm{O}_{3} \mathrm{~S}-\mathrm{bim}-\mathrm{C}_{4} \mathrm{H}_{5} \mathrm{O}_{4}\right] \mathrm{Cl}$.

Lewis complex is close to $1450 \mathrm{~cm}^{-1}$. By observing these two peaks, the acidic type of a sample can be determined [6]. The characterization procedure in this work was as follows: the ionic liquids were heated and dissolved first, and then mixed with pyridine by a volume ratio of 5:2. The FT-IR spectra were finally obtained as shown in Figure 1. Compared with the spectra of pyridine, two new absorption peaks near 1540 and $1450 \mathrm{~cm}^{-1}$ appeared in the FT-IR spectra of Py + BLILs-1 and Py + BLILs-2, suggesting that both BLILs-1 and BLILs-2 show Brøn-

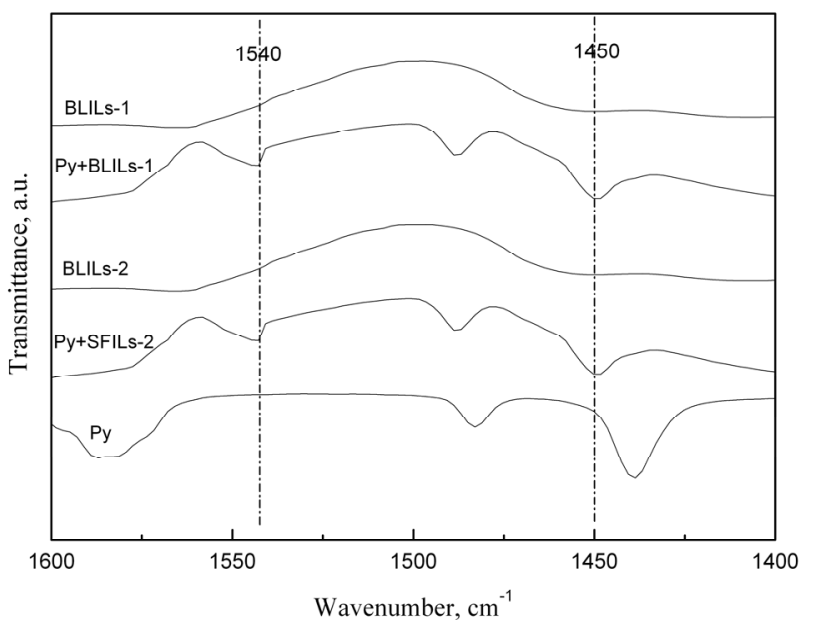

Figure 1. Py-IR spectra of samples. sted and Lewis acidity.

The acid strength values $\left(H_{0}\right)$ of the ionic liquids were determined by the UV-visible spectroscopy combined with Hammett indicator method at room temperature [13]. From Table 1 it can be seen that $H_{0}$ values of the BLILs1 and BLILs- 2 were 5.6 and 4.2, respectively, indicating that the acid strength of BLILs-2 is higher than that of BLILs-1. The acid amount of the two Brønsted-Lewis acidic ionic liquids determined by acid-base titration was $2.0 \mathrm{~mol} \mathrm{NaOH} / \mathrm{mol} \mathrm{BLILs}-1$ and $3.0 \mathrm{~mol} \mathrm{NaOH} / \mathrm{mol}$ BLILs-2, respectively. The number of moles of $-\mathrm{COOH}$ in BLILs-2 $(2.0 \mathrm{~mol})$ were more than that in BLILs-1 $(1.0 \mathrm{~mol})$, which may be responsible for the higher acid strength and acid amount of BLILs-2.

The melting points of BLILs- 1 and BLILs-2 were $80^{\circ} \mathrm{C}-81^{\circ} \mathrm{C}$ and $85^{\circ} \mathrm{C}-86^{\circ} \mathrm{C}$, respectively, so the Brønsted-Lewis acidic ionic liquids with lower melting point

Table 1. The acid strength and acid amount of BrønstedLewis acidic ionic liquids ${ }^{a}$.

\begin{tabular}{ccc}
\hline BLILs & $H_{0}$ & Acid amount (mol NaOH/mol BLILs) \\
\hline BLILs-1 & $5.6^{\mathrm{b}}$ & 2.0 \\
BLILs-2 & $4.2^{\mathrm{c}}$ & 3.0 \\
\hline
\end{tabular}

${ }^{\mathrm{a}} H_{0}=\mathrm{p} K_{\mathrm{a}}+\log ([\mathrm{I}] /[\mathrm{HI}]$, acid amount was measured by acid-base titration ${ }^{\mathrm{b}}$ Indicator: methyl red; ${ }^{\mathrm{c}}$ Indicator: dimethyl yellow. 
are expected to be synthesized by changing the structures of anions or cations in the future, which are more beneficial for the applications of Brønsted-Lewis acidic ionic liquids in catalysis.

\section{Conclusion}

Two novel Brønsted-Lewis acidic ionic liquids, $\left[\mathrm{CH}_{3}\right.$ $\mathrm{COO}-\mathrm{Zn}-\mathrm{O}_{3} \mathrm{~S}$-bim- $\left.\mathrm{CH}_{2} \mathrm{CH}_{2} \mathrm{COOH}\right] \mathrm{Cl}$ and $\left[\mathrm{CH}_{3} \mathrm{COO}-\mathrm{Zn}-\right.$ $\mathrm{O}_{3} \mathrm{~S}$-bim- $\left.\mathrm{C}_{4} \mathrm{H}_{5} \mathrm{O}_{4}\right] \mathrm{Cl}$, were synthesized and characterized in this paper. Compared with $\left[\mathrm{CH}_{3} \mathrm{COO}-\mathrm{Zn}-\mathrm{O}_{3} \mathrm{~S}-\right.$ bim$\left.\mathrm{CH}_{2} \mathrm{CH}_{2} \mathrm{COOH}\right] \mathrm{Cl}$, [ $\mathrm{CH}_{3} \mathrm{COO}-\mathrm{Zn}-\mathrm{O}_{3} \mathrm{~S}-$ bim- $\left.\mathrm{C}_{4} \mathrm{H}_{5} \mathrm{O}_{4}\right] \mathrm{Cl}$ has a higher acid strength and acid amount. However, their melting points are rather high from the view of application as a solvent or a catalyst. A further attempt will be made to lower the melting point by adjusting the substitute group in cation or matching anion with cation.

\section{Experimental}

\subsection{Materials}

Imidazole was purchased from Tianjin Guangfu Fine Chemical Research Institute; ethyl acrylate was obtained from Tianjin Chemical Reagent Co., Ltd.; diethyl maleate was purchased from Tianjin Kemiou Chemical Reagent Co., Ltd.; 1,4-butane sultone was supplied by Wuhan Fengfan Chemical Co., Ltd.; $\mathrm{Zn}(\mathrm{OAc})_{2} \cdot 2 \mathrm{H}_{2} \mathrm{O}$ was purchased from Tianjin Jiangtian Chemical Technology Co., Ltd. All the materials above were of analytical grade and used without further purification except that anhydrous zinc acetate was obtained by removal of crystal water from $\mathrm{Zn}(\mathrm{OAc})_{2} \cdot 2 \mathrm{H}_{2} \mathrm{O}$ at $373 \mathrm{~K}$ for $2 \mathrm{~h}$, and 1,4-butane sultone was purified by distillation before use.

\subsection{Characterization Procedures}

The Fourier transform infrared (FT-IR) spectra of the ionic liquids were recorded on a Bruker Vector 22 infrared spectroscopy (liquid film or $\mathrm{KBr}$ pellet) between 400 and $4000 \mathrm{~cm}^{-1}$ and collected at a resolution of $4 \mathrm{~cm}^{-1} \cdot{ }^{1} \mathrm{H}$ NMR spectra were recorded on a Bruker Avance 400 instrument in $\mathrm{D}_{2} \mathrm{O}$ with TMS as the external standard. Elemental analysis of the ionic liquids was performed with a Vairo EL elemental analysis instrument. The acid strength of ionic liquids was determined by the UV-visible spectroscopy combined with Hammett indicator method, which was recorded on a Cary 300 UV-visible spectroscope at room temperature.

\subsection{Preparation of Ionic Liquids}

The synthesis approach of the Brønsted-Lewis acidic ionic liquids consists of four steps. Take BLILs-1 as an example.

\subsubsection{1-Ethoxycarbonylethylene Imidazole (IP-1)} Imidazole $(0.5 \mathrm{~mol})$, ethyl acrylate $(0.55 \mathrm{~mol})$ and sol- vent toluene were charged into a $250 \mathrm{~mL}$ three-necked flask equipped with a mechanical stirrer. Then the mixture was heated to $100^{\circ} \mathrm{C}$ for $24 \mathrm{~h}$ under vigorous stirring. After that, toluene and remaining ethyl acrylate were distilled off from the reaction mixture under vacuum at $100^{\circ} \mathrm{C}$ and a brown liquid IP-1 was obtained.

\subsubsection{1-Ethoxycarbonylethylene-3-(4-Sulfobutyl) Imidazole (IP-2)}

IP-1 $(0.2 \mathrm{~mol})$ and 1,4-butane sultone $(0.2 \mathrm{~mol})$ were stirred at $50^{\circ} \mathrm{C}$ for $12 \mathrm{~h}$, and a viscous liquid was obtained. The reaction mixture was washed by toluene and ethyl ether for three times, respectively. The viscosity got larger with washing operation, and then a gelatinous substance was obtained. The gelatinous substance was dried to constant weight in vacuum to afford IP-2 in the form of white solid at room temperature.

\subsubsection{1-Carboxyethylene-3-(4-Sulfobutyl) Imidazolium Chloride (IP-3)}

IP-2 $(0.1 \mathrm{~mol})$ was dissolved in distilled water and then excessive $\mathrm{HCl}$ was added dropwise into the aqueous solution of IP-2 with vigorous stirring at room temperature. After that, the mixture was heated to $100^{\circ} \mathrm{C}$ and kept for $2 \mathrm{~h}$. Water, remaining $\mathrm{HCl}$ and byproduct ethanol were removed by distillation under vacuum at $100^{\circ} \mathrm{C}$, and the resultant viscous liquid was dried to constant weight under vacuum at $100^{\circ} \mathrm{C}$ to give a Brønsted acidic ionic liquid IP-3.

\subsubsection{1-Carboxyethylene-3-(4-Zinc Acetate Sulfobutyl) Imidazolium Chloride (BLILs-1)}

IP-3 (0.1 mol) was dissolved in distilled water, and then anhydrous zinc acetate $(0.1 \mathrm{~mol})$ was added into the aqueous solution of IP-3. The mixture was stirred and heated to $50^{\circ} \mathrm{C}$ and kept for $4 \mathrm{~h}$. Water was removed by vacuum distillation at $100^{\circ} \mathrm{C}$, and the obtained viscous liquid was dried to constant weight under vacuum at $100^{\circ} \mathrm{C}$ to give the Brønsted-Lewis acidic ionic liquid BLILs-1 as a solid at room temperature.

BLILs-2 was prepared in a similar way and the difference was that diethyl maleate was used as a substitute for ethyl acrylate to introduce Bronsted acid site.

\section{Characterization}

\subsection{1-Carboxyethylene-3-(4-Zinc Acetate Sulfobutyl) Imidazolium Chloride (BLILs-1)}

\subsubsection{1-Ethoxycarbonylethylene-3-(4-Sulfobutyl) Imidazole (IP-2)}

FTIR(KBr): 1040, 1202, 1378, 1456, 1566, 1645, 1730, 2937, 2982, 3093, $3142 \mathrm{~cm}^{-1}$. 


\subsubsection{1-Carboxyethylene-3-(4-Sulfobutyl) Imidazolium Chloride (IP-3)}

FTIR(KBr): 1038, 1162, 1414, 1453, 1566, 1725, 2853, 2924, 3104, 3145, $3406 \mathrm{~cm}^{-1}$.

\subsubsection{1-Carboxyethylene-3-(4-Zinc Acetate Sulfobutyl) Imidazolium Chloride (BLILs-1)}

FTIR(KBr): 1040, 1162, 1406, 1620, 1721, 2962, 3107, $3145,3429 \mathrm{~cm}^{-1} .{ }^{1} \mathrm{H}$ NMR $\left(\mathrm{D}_{2} \mathrm{O}, \delta, 400 \mathrm{MHz}\right) \delta \mathrm{ppm}$ : $1.755\left(2 \mathrm{H}, \mathrm{m},-\mathrm{CH}_{2}-\right), 1.975\left(3 \mathrm{H}, \mathrm{s},-\mathrm{CH}_{3}\right), 2.032(2 \mathrm{H}$, $\left.\mathrm{m},-\mathrm{CH}_{2}-\right), 2.785^{[14]}\left(2 \mathrm{H}, \mathrm{t},-\mathrm{CH}_{2}-\mathrm{COOH}\right), 2.956^{[15]}(2 \mathrm{H}$, t, S-CH $\left.2_{2}^{-}\right), 4.250^{[6]}\left(2 \mathrm{H}, \mathrm{t},-\mathrm{CH}_{2}-\mathrm{N}\right), 4.421^{[14]}(2 \mathrm{H}, \mathrm{t}$, $\left.\mathrm{N}-\mathrm{CH}_{2}-\right), 7.509^{[14]}(1 \mathrm{H}, \mathrm{d}, \mathrm{C}=\mathrm{CH}-\mathrm{N}), 7.515^{[14]}(1 \mathrm{H}, \mathrm{d}$, $\mathrm{N}-\mathrm{CH}=\mathrm{C}), 8.805^{[14]}(1 \mathrm{H}, \mathrm{s}, \mathrm{N}=\mathrm{CH}-\mathrm{N})$. Anal.Calcd for BLILs-1: C 34.13\%, H 4.58\%, N 6.93\%, S 7.34\%, Cl $8.15 \%$; Found: C 34.31\%, H 4.81\%, N 6.70\%, S 7.05\%, $\mathrm{Cl} 7.89 \%$

\subsection{1-(1,2-Dicarboxy) Ethylene-3-(4-Zinc Acetate Sulfobutyl) Imidazolium Chloride (BLILs-2)}

\subsubsection{1-(1,2-Diethoxycarbonyl) Ethylene Imidazole (IP-4)}

${ }^{1} \mathrm{H}$ NMR $\left(\mathrm{D}_{2} \mathrm{O}, \delta, 400 \mathrm{MHz}\right) \delta$ ppm: $1.092\left(3 \mathrm{H}, \mathrm{t}, \mathrm{H}_{3} \mathrm{C}-\right)$, $1.191\left(3 \mathrm{H}, \mathrm{t}, \mathrm{H}_{3} \mathrm{C}-\right), 3.176\left(2 \mathrm{H}, \mathrm{d},-\mathrm{CH}_{2}-\right), 4.067(2 \mathrm{H}, \mathrm{q}$, $\left.-\mathrm{CH}_{2}-\right), 4.140\left(2 \mathrm{H}, \mathrm{q},-\mathrm{CH}_{2}-\right), 5.436(1 \mathrm{H}, \mathrm{t},-\mathrm{CH}-), 6.958$ $(1 \mathrm{H}, \mathrm{d}, \mathrm{C}=\mathrm{CH}-\mathrm{N}), 7.138(1 \mathrm{H}, \mathrm{d}, \mathrm{N}-\mathrm{CH}=\mathrm{C}), 7.700(1$ $\mathrm{H}, \mathrm{s}, \mathrm{N}=\mathrm{CH}-\mathrm{N})$.

\subsubsection{1-(1,2-Diethoxycarbonyl) Ethylene-3- (4-Sulfobutyl) Imidazole (IP-5)}

${ }^{1} \mathrm{H}$ NMR $\left(\mathrm{D}_{2} \mathrm{O}, \delta, 400 \mathrm{MHz}\right) \delta$ ppm: $1.184(6 \mathrm{H}, \mathrm{m}$, $\left.\mathrm{H}_{3} \mathrm{C}-\right), 1.688\left(2 \mathrm{H}, \mathrm{m},-\mathrm{CH}_{2}-\right), 1.976\left(2 \mathrm{H}, \mathrm{m},-\mathrm{CH}_{2}-\right)$, $2.830\left(2 \mathrm{H}, \mathrm{t},-\mathrm{CH}_{2}-\right), 3.368\left(2 \mathrm{H}, \mathrm{d},-\mathrm{CH}_{2}-\right), 4.129(2 \mathrm{H}, \mathrm{t}$, $\left.-\mathrm{CH}_{2}-\right), 4.217\left(4 \mathrm{H}, \mathrm{m},-\mathrm{CH}_{2^{-}}\right), 5.701(1 \mathrm{H}, \mathrm{t},-\mathrm{CH}-)$, $7.476(1 \mathrm{H}, \mathrm{d}, \mathrm{C}=\mathrm{CH}-\mathrm{N}), 7.561(1 \mathrm{H}, \mathrm{d}, \mathrm{N}-\mathrm{CH}=\mathrm{C})$, $8.881(1 \mathrm{H}, \mathrm{s}, \mathrm{N}=\mathrm{CH}-\mathrm{N})$.

\subsubsection{1-(1,2-dicarboxy) Ethylene-3-(4-Sulfobutyl) Imidazolium Chloride (IP-6)}

${ }^{1} \mathrm{H}$ NMR $\left(\mathrm{D}_{2} \mathrm{O}, \delta, 400 \mathrm{MHz}\right) \delta$ ppm: $1.573(2 \mathrm{H}, \mathrm{m}$, $\left.-\mathrm{CH}_{2}-\right), 1.819\left(2 \mathrm{H}, \mathrm{m},-\mathrm{CH}_{2}-\right), 2.737\left(2 \mathrm{H}, \mathrm{t},-\mathrm{CH}_{2}-\right)$, $3.187\left(2 \mathrm{H}, \mathrm{d},-\mathrm{CH}_{2}-\right), 4.078\left(2 \mathrm{H}, \mathrm{t},-\mathrm{CH}_{2}-\right), 5.489(1 \mathrm{H}, \mathrm{t}$, -CH-), $7.400(1 \mathrm{H}, \mathrm{d}, \mathrm{C}=\mathrm{CH}-\mathrm{N}), 7.474(1 \mathrm{H}, \mathrm{d}, \mathrm{N}-\mathrm{CH}=$ C), $8.851(1 \mathrm{H}, \mathrm{s}, \mathrm{N}=\mathrm{CH}-\mathrm{N})$.

\subsubsection{1-(1,2-Dicarboxy) Ethylene-3-(4-Zinc Acetate Sulfobutyl) Imidazolium Chloride (BLILs-2)}

FTIR (KBr): 728, 1038, 1160, 1399, 1570, 1630, 1730, $2968,3147,3416 \mathrm{~cm}^{-1} .{ }^{1} \mathrm{H}$ NMR $\left(\mathrm{D}_{2} \mathrm{O}, \delta, 400 \mathrm{MHz}\right)$

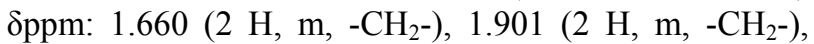
$1.929\left(3 \mathrm{H}, \mathrm{s},-\mathrm{CH}_{3}\right), 2.897\left(2 \mathrm{H}, \mathrm{t},-\mathrm{CH}_{2}-\right), 3.116(2 \mathrm{H}, \mathrm{d}$,
$\left.-\mathrm{CH}_{2}-\right), 4.138\left(2 \mathrm{H}, \mathrm{t},-\mathrm{CH}_{2}-\right), 5.154(1 \mathrm{H}, \mathrm{t},-\mathrm{CH}-), 7.412$ $(1 \mathrm{H}, \mathrm{d}, \mathrm{C}=\mathrm{CH}-\mathrm{N}), 7.458(1 \mathrm{H}, \mathrm{d}, \mathrm{N}-\mathrm{CH}=\mathrm{C}), 8.856(1$ $\mathrm{H}, \mathrm{s}, \mathrm{N}=\mathrm{CH}-\mathrm{N})$. Anal.Calcd for BLILs-2: C $32.56 \%, \mathrm{H}$ $3.97 \%$, S $6.68 \%$, N 5.84\%, Cl 7.31\%; Found: C 30.81\%, H $3.90 \%$, S $6.76 \%$, N $6.02 \%, \mathrm{Cl} 7.47 \%$.

\section{Acknowledgements}

The authors are grateful to the Special Program of National Basic Research Program of China (973 Program) (Grant 2010CB234602), National Natural Science Foundation of China (Grant 21076059), the Natural Science Foundation of Tianjin City (Grant 12JCYBJC12800), and the Key Basic Program of Applied Basic Research Plan of Hebei Province (Grant 12965642D).

\section{REFERENCES}

[1] L. J. Jia, Y. Y. Wang, H. Chen, Y. K. Shan and L. Y. Dai, "Alkylation of Benzene with 1-Hexene in Acidic Ionic Liquid Systems: $\mathrm{Et}_{3} \mathrm{NHCl}_{-} \mathrm{FeCl}_{3}$ and $\mathrm{Et}_{3} \mathrm{NHCl}-\mathrm{AlCl}_{3}$ Ionic Liquids," Reaction Kinetics and Catalysis Letters, Vol. 86, No. 2, 2005, pp. 267-273.

doi:10.1007/s11144-005-0321-3

[2] A. C. Cole, J. L. Jensen, I. Ntai, K. L. Tran, K. J. Weaver, D. C. Forbes and J. H. Davis Jr., "Novel Brønsted Acidic Ionic Liquids and Their Use as Dual Solvent-Catalysts," Journal of the American Chemical Society, Vol. 124, No. 21, 2002, pp. 5962-5963. doi:10.1021/ja026290w

[3] L. M. Liu, F. Li, Y. J. Wang and X. Q. Zhao, "One Step Synthesis of Methylene Diphenyl Dicarbamate," Chinese Journal of Catalysis, Vol. 28, No. 8, 2007, pp. 667-669. doi:10.1016/S1872-2067(07)60057-6

[4] X. H. Wang, G. H. Tao, Z. Y. Zhang and Y. Kou, "Synthesis and Characterization of Dual Acidic Ionic Liquids," Chinese Chemical Letters, Vol. 16, No. 12, 2005, pp. 1563 1565.

[5] S. W. Liu, C. X. Xie, S. T. Yu and F. S. Liu, "Dimerization of rosin using Brønsted-Lewis Acidic Ionic Liquid as Catalyst," Catalysis Communication, Vol. 9, No. 10, 2008, pp. 2030-2034. doi:10.1016/j.catcom.2008.03.045

[6] S. W. Liu, H. X. Zhou, S. T. Yu, C. X. Xie, F. S. Liu and Z. Q. Song, "Dimerization of Fatty Acid Methyl Ester Using Bronsted-Lewis Acidic Ionic Liquid as Catalyst," Chemical Engineering Journal, Vol. 174, No. 1, 2011, pp. 396-399. doi:10.1016/j.cej.2011.09.017

[7] S. W. Liu, C. X. Xie, S. T. Yu, M. Xian and F. S. Liu, “A Bronsted-Lewis Acidic Ionic Liquid: Its Synthesis and Use as the Catalyst in Rosin Dimerization," Chinese Journal of Catalysis, Vol. 30, No. 5, 2009, pp. 401-406. doi:10.1016/S1872-2067(08)60109-6

[8] S. T. Yu, S. W. Liu, F. S. Liu, C. X. Xie and K. H. Ji, “A Bronsted-Lewis Acidic Ionic Liquid and Its Application in the Reaction of Rosin Dimerization," CN Patent No. 101191035 B, 2010.

[9] S. W. Liu, L. Li, S. T. Yu, C. X. Xie, F. S. Liu and Z. Q. Song, "Polymerization of Fatty Acid Methyl Ester Using Acidic Ionic Liquid as Catalyst," Chinese Journal of Ca- 
talysis, Vol. 31, No. 11-12, 2010, pp. 1433-1438. doi:10.1016/S1872-2067(10)60128-3

[10] N. N. Quan, S. H. Bao and J. G. Yang, "Highly Efficient Procedure for the Conjugate Addition of Amines to Electron-Deficient Alkenes Catalyzed by Novel Ionic Liquid," Chinese Science Bulletin, Vol. 55, No. 23, 2010, pp. 25122516. doi:10.1007/s11434-010-3147-y

[11] X. Liang and C. Qi, "Synthesis of a Novel Ionic Liquid with both Lewis and Bronsted Acid Sites and Its Catalytic Activities," Catalysis Communication, Vol. 12, No. 9, 2011, pp. 808-812. doi:10.1016/j.catcom.2011.01.018

[12] X. Jiang, W. Ye, X. Song, W. Ma, X. Lao and R. Shen, "Novel Ionic Liquid with both Lewis and Bronsted Acid Sites for Michael Addition," International Journal of Molecular Sciences, Vol. 12, No. 11, 2011, pp. 7438-7444. doi:10.3390/ijms 12117438
[13] Y. L. Geng, L. Y. Hu, X. Q. Zhao, H. L. An and Y. J. Wang, "Synthesis of 4, 4'-MDC in the Presence of Sulfonic Acid-Functionalized Ionic Liquids," Chinese Journal of Chemical Engineering, Vol. 17, No. 5, 2009, pp. 756760. doi:10.1016/S1004-9541(08)60273-6

[14] Z. F. Fei, D. B. Zhao, T. J. Geldbach, R. Scopelliti and P. J. Dyson, "Brønsted Acidic Ionic Liquids and Their Zwitterions: Synthesis, Characterization and $\mathrm{pKa}$ Determination," Chemistry: A European Journal, Vol. 10, No. 19, 2004, pp. 4886-4893. doi:10.1002/chem. 200400145

[15] X. F. Liu, L. F. Xiao, H. Wu, Z. Li, J. Chen and C. G. Xia, "Novel Acidic Ionic Liquids Mediated Zinc Chloride: Highly Effective Catalysts for the Beckmann Rearrangement," Catalysis Communications, Vol. 10, No. 5, 2009, pp. 424-427. doi:10.1016/j.catcom.2008.09.007 